\title{
CHILDREN CHALLENGING THE DESIGN OF HALF- BAKED GAMES: EXPRESSING VALUES THROUGH THE PROCESS OF GAME MODDING
}

\author{
Chronis Kynigos*(Corresponding author) \\ kynigos@ppp.uoa.gr
}

Educational Technology Lab, National and Kapodistrian University of Athens

School of Philosophy, Faculty of Pedagogy,

University Campus

Zografou, Athens, Greece

PC 15703

$+302107277508$

NikoletaYiannoutsou
nyiannoutsou@ppp.uoa.gr

Educational Technology Lab, National and Kapodistrian University of Athens

\begin{abstract}
In this paper we look at the potential educational value of placing children in a dual role of identifying and changing rules and values embedded in digital games by hacking them. Children's participation in the design of learning technologies is a difficult challenge to address, due to limitations in children's domain-knowledge around which these technologies are developed. Their role in the design process is thus usually limited to that of a user or tester. In this paper we discuss the role of children as "hackers" of what we call 'half-baked' games. By hacking a pedagogically engineered half-baked game in order to improve or change it, children are expected to challenge the values, the mechanics and the rules of a fully functioning, but faulty, or inappropriate game originally designed to provoke students to modify it. This discussion uses an example of children modding such a game provocatively called 'PerfectVille', which was specially designed to raise problems around the issue of urban sustainability. The game itself was designed with the use of a GIS rule-based authoring tool for game design called 'sus- $x$ '. The children grappled with both value-laden issues and concepts embedded in the tool they used. The issue of taking children's values into account but also of helping them to build understandings of wider contested societal values can be addressed by studying the process by which children design and change games affording such experiences. It also illuminated their own perspective and values, which they embedded in the games.
\end{abstract}

KEYWORDS : urban sustainability; game modding; learning through design; coexisting values and rules; 


\section{BACKGROUND}

In the past decade, the issue of the many ways in which values are embedded in games and the task for game designers to be more conscious of the values they expressly or implicitly embed in games has drawn serious attention. Flanagan and Nissenbaum [1] recently developed a framework for designers to identify values in games and to consciously embed values in those they design themselves. Supporting those designers thus has been addressed as a professional development task either within a corporate context or in specialised courses in tertiary education. This special issue focuses on how values, assumptions and views of children and childhood are embedded in a design and the extent to which this is made explicit. It also addresses the potential roles children themselves can play in a design. In this paper we study children's values on issues of urban sustainability as they are expressed while modding a game together with the researchers. We admit to an educational research agenda, i.e. that we aimed to understand and support children's ideas and sensitivities on this complex issue. At the same time, however, we suggest that their activity as hackers of a game which we purposefully gave them to be wanting, can be usefully read as adopting the role of design partners [2] starting from a game in order to improve it. In this sense, this kind of engaged activity provided us with deep insights into student values as they expressed them while changing the rules of the game. Engineering 'half-baked' artefacts is a technique we have adopted aiming to engage children in constructionist activity focusing on the issues in question as they hack or mod the artefact, in this case the game [3].

However, in the world of primary and secondary education, game play and also game design has been addressed as a learning process, originally not so much with respect to values but more to do with learning domain specific concepts. During design and play, the discrimination and use of the rules embedded in a game help learners to generate meanings e.g. around powerful STEM ideas. Collaborative game play and design provide a context where these ideas are discussed and argued over further enhancing the process of meaning making. These ideas however are often situated in the context of a game where values reside.

In this paper we discuss how hacking a half-baked game with children can provide opportunities to illuminate their meaning making in STEM and at the same time becoming more sensitive and articulate about personal and societal values. We 
studied 13-15 year olds' design processes with tools affording them with the role of game hackers, i.e. re-designing or modding digital games as our design partners. We looked at both how the students identified values embedded in the half-baked game and how they questioned and changed them while changing the game itself. This process provides insight into student values but also enhances their consciousness and sensitivity to values within games. In parallel, it may provide new insight to the designers themselves both on the values they embed while designing games and those children may have while playing them. We thus discuss the challenge and the educational value of integrating attention to both powerful STEM ideas and values within game design projects for high - school students.

\section{FRAMEWORK: DESIGN THINKING WITH GAME DESIGN}

The issue of designing tools for children to learn by means of designing games and models has inspired interesting discussion around education in the Interaction Design and Children (IDC) community [4]. These kinds of tools invite children to address, question and discuss the rules, values and content of games. Special attention has been given to 'Game modding' [5], i.e. making changes and re-mixing an existing game and in particular the ways in which modding may further invite children to identify values and rules by means of playing the game and then to find and employ the affordances allowing them to make the changes they choose [6]. In this paper we discuss the design of half-baked tools to intentionally invite children to make changes to games based on their views on the mathematical - logical aspect of the rules and at the same time the values that these rules may embed [3]. By addressing logical aspects of a game as a means to discuss and grapple with value-laden aspects, students are confronted with complex, contextual issues. In this paper we take the example of such a complex contentious issue, that of urban sustainability. The educational paradigm here is not just to generate meanings around important and powerful mathematical or scientific ideas $[7,5]$. It is to appreciate the complexity of multi-faceted, elusive, trans-disciplinary, contested issues where powerful ideas are just tools to grapple with values and diverse points of view of the same problem $[8,9$, 5]. It is also to provide a context for students to generate creative ideas and innovative games by means of meshing domain concepts with values. Researchers have in recent years given attention to the creative potential of 'values conscious design' and have 
developed methods to support it such as for instance a method called 'Values at play' connecting personal experiences with idea production, paper prototyping and value explication through discussion [10].

In this paper we discuss how students made changes to a game, which we specially designed for them to change [5], based on sustainability, sustainable lifestyles, and the essence of a sustainable city. We were looking to understand how hacking a game can facilitate learners to generate meanings and express and discuss personal and social values in the process of coming up with creative game ideas.

Games have been an integral part of society since ancient times [11,12]. They are an expression of play allowing people to go beyond immediate imagination and direct physical activity. They have been associated with recreation, engagement and roleplay. They have embedded features like risk, initiative, reaction, chance, strategy, coordination, physical skill, situational roles. A special genre of games have implicitly or explicitly been associated with learning. However, game players have not always perceived these games as genuine games.

In this paper we discuss students modding games and in that sense acting as hackers, i.e. game designers or re-designers. We address the educational value of such an activity with specially designed games. Game design has not in general been considered as game play in itself or as part of game play. It has typically been considered as a professional skill. However, players have been inventing and coining new games since ancient times, moving from what Caillois [11] terms to be "paidia" that evokes wild, free-form experimental types of play to "ludus" constituting defined, ruled play. These definitions of play exist on a sliding scale allowing ruled games to be reconsidered and transformed through experimentation and negotiation.

So, with our tool for modding a game on urban sustainability, we moved from a model of games as closed systems to approaches perceiving gaming as 'procedural literacy' $[11,13,14]$. Gamers learn through understanding the components of the game system in terms of play and game mechanics as linked to programming techniques. At the same time, they also reflect on and influence the role these games may play in a wider cultural context. Here, we thus discuss design-thinking processes as essentially learning processes through playful creation that is of benefit to the learner, to society at large and to the games industry. At the same time, such processes become particularly visible to us as the children's design partners and thus illuminative with respect to their values and meanings. In this respect the partnership between 
researchers an students becomes a context facilitating elaboration, helping us develop our understanding of their participation in the design process [15].

Digital tools may invite students to use a huge variety of affordances to construct and/or re-mix games. Games become both the tool to think with and the end production in a design thinking process. Learners' experience of designing and modding the object, the rules and the roles of the players can promote societal values, 21 st century life/career skills, competences and dispositions.

The study of learning with games has predominantly focused on game play (see for example [16]). With the proliferation of digital technologies in education, game play has been revisited and a new dimension related to games emerged: that of game design. Game design as a learning activity appeared in the context of Constructionism [17] where learning is connected to learner constructions -in this case games- with personal meaning [18]. After that, several studies focused on the learning dimensions of engaging students in game design (see for example [19,20]). In this line of research game design is identified as an activity for contextualized domain learning (i.e. mathematics, programming, language and history) but also as a context where $21 \mathrm{st}$ century skills, values and ways of thinking emerge (i.e. design thinking, values conscious design etc). Recent studies focus also on the factors influencing the process of game design by children revealing the importance of audience [21].

Research on learning through Game Design has explored game design in general focusing on the different game design platforms used to support domain learning and design thinking [19]. A distinct part of this research focuses on the modification of existing and malleable popular digital games (i.e modding). Modification of games is an activity where designers and players co-exist in the sense that game modding can be one of the practices employed by designers in order to come up with ideas for new games. However, first and foremost game modding is a practice employed by gamers: mods -i.e. modifications of games- are digital artefacts that avid gamers design by tinkering with their favourite games [22].

\section{1 Half-baked games for learning through hacking}

The support of learning through game modding involves a pedagogical engineering approach. Educationalists and researchers engage in design based research aiming to craft malleable games inviting modding and at the same time to embed concepts, values and content in such games so that modding will enhance meaning-making in 
learners. An example at the heart of engineering malleable games is the idea of 'halfbaked' microworlds (in this case games) coined by Kynigos [23]: half-baked microworlds are exploratory digital environments which, by design, call for modification and change by teachers and students. Half-baked games are artefacts which are incomplete or buggy and are mediated to students as such inviting them to act as hackers in the role of improving or debugging them. Game modding practice is a process by which modders decide what to change in the game by tinkering with game mechanics and content. In the idea of half-baked games, there is an explicit or a tacit embedded pedagogical agenda and potentially teacher orchestrations. Extending this idea to game hacking or re-design, a half-baked game for modding would thus be designed so that it is mediated and perceived as embedding the wrong values or messages, as embedding a faulty gaming idea, as wanting or improvable or simply malleable.

Modding has hitherto mainly been considered as a fun, relevant and entrepreneurial activity in itself outside the education sector. The gaming industry has embraced and supported this practice given the strong social dimension of modding, its widespread use, its role in raising engagement with the game [22] its role in the success of the game among the communities of gamers, its power as a game refining tool [24]. Thus, several gaming companies have released along with their Games, Game Design Kits that support game modding; for example Moshirnia [25], describes the modding tool for Civilization IV; Robertson \& Howells, [26] refer to the use of the free tool-kit accompanying the NeverWinterNights game. Games such as LittleBigPlanet also allow for the creation and sharing of new levels amongst the game playing community using built-in design tools and encouraging what can be discussed as a craft practice, tinkering with existing gameplay kits, textures, character designs and restructuring the "miniature world" of the game [27]. Furthermore game design platforms such as the Game Maker support modding by offering tools to modify a set of well-known sample games, implemented with the game engine of the platform [28]. Most of these tools are designed to support modding by non-technical users (i.e. knowing a programming language for example). Modding is thus an end-user practice, involving important engagement with an already existing game.

Taking an educational perspective however poses the question of what are the advantages of modding as a learning activity over game design from scratch? One response, relates to the very nature of modding, which allows focusing on what is 
important for the design of the game because the game engine eliminates the overhead of building a convincing product [29]. Studies investigating modding as learning activity, have used modding tools like the ones we described above, to support the learning of programming languages, and skills related to design thinking $[26,30]$. Only recently studies introduced the idea of using modding to pursue domain learning. Moshirnia [25] for example, focuses on History Learning with a mod of Civilization IV, but the modders in this study are the teachers. Baytak, Land and Smith [28] explore how modding with Game Maker can facilitate learning of concepts related to nutrition. An example of the games modified by students in this study, is an instance of pac-man where the goal of the player was to avoid unhealthy food instead of ghosts. Monterrat, Lavoué and George [31], introduce more strongly the idea of domain learning describing it as "modding to learn the content of the learning game". Their research focuses on Language Learning through modding a game designed for learning Esperanto.

The latter two studies [31,28], focusing on domain learning, do not provide data documenting the learning experience. Thus, our inferences on learning inevitably focus on the characteristics of the games: it seems that in both cases, learning is not essentially integrated in game mechanics: i.e students can change some variables of the game (i.e. replacing ghosts with unhealthy food), but they don't manipulate the model of the game (i.e a balanced diet). Furthermore, despite the fact that both studies focus on domain learning, the modding tools used for this purpose are bound by the way the game engine implements the game and the pedagogical agenda is imposed ad hoc on the game. So what about the issue of embedded values in a game?

From a pedagogical engineering point of view, the way content, concepts and values are integrated in games is a critical factor determining the quality of learning experience: learning in serious games depends -apart from pedagogy and game mechanics- on the integration of content so that learning is intrinsic to play [30]. The two different approaches in integrating learning in games is depicted in the terms endogenous (i.e. "games in which context and gameplay are inextricably linked") and exogenous games ("games in which context is extrinsic to game play") used by Squire [33]. Elaborating on the difference between these two approaches explains that knowledge in exogenous games involves discrete facts - true by authority- whereas in endogenous games knowledge is a toolset to solve problems. Similarly, instruction in exogenous games involves transmission of information and content whereas in 
endogenous games instruction involves confronting existing beliefs and values, performing skills in context and reflecting on player's understandings.

We thus argue that in order to offer rich learning opportunities while students engage in game modding we need endogenous tools that will allow them to access, tweak and change the model of the game and its underlying value assumptions which we mentioned earlier. To better explain this, we need to refer to the criticism pinpointing that simplified, for instance, values inherent in games like the Sims or SimCity become unquestionably accepted [34] and create or reproduce false perceptions of reality. An example of such a value is drawn from "The Sims": "Class mobility is somewhat idealized and segregated, once a Sim enters the game his wealth level can increase but never drop" [35]. This is not to say that games should be realistic representations of the world. On the contrary, these simplistic values are important because they ensure playability and easy entry point for the game. We argue, however, that learning in these games is better facilitated if we focus on challenging these models.

So, in this paper we discuss the design of a game modding tool, which was developed with the intention to engage students in discussing and grappling with a complex value-laden issue, urban sustainability. Our research aimed at investigating the expressive power of this tool when integrated in the context of a specific pedagogical intervention where students play a half-baked game, challenge its basic axiom and then modify it creating a new functional game. Are important issues concerning urban sustainability raised and discussed while modding a half-baked sustainability game? Can rules and values related to the game and the issue at hand form an integral context for learners to gain sensitivity to complex sustainability issues? Can modding be a powerful contextualisation of domain concepts in complex societal issues?

The tool was designed so that the students would in parallel use and generate meanings around computational ideas such as programming, event handling and geolocated data handling.

\section{METHOD}

The approach we used to develop accounts of student learning in the social context of a classroom activity, consisted of the following elements: i) Iterative design of a pedagogical intervention aiming to introduce the digital artifact of half-baked games based on the theoretical perspective of games as expressive media [33]; ii) 
Investigating student interaction with the technology in the social context of a classroom iii) Developing accounts on student learning and drawing inferences on design aspects of half -baked games as expressive media; iv) Using data-grounded inferences to inform the initial theoretical background about the appropriateness of half-baked games as instruments for children to think about, formulate and express their values. Research of this type falls under the category of Design based research in that it involves a theoretical grounding of both pedagogical and technological design; It is theory based; It is contextualized; It focuses on refining our understanding of student activity based not only on summative results (success or failure) but on contextualized interactions of students with the learning environment; It informs and refines theory [36-38].

The research we report here, had two phases. In the first phase we used a generic version of our tool, which we called 'Sus-x', we gave it this name, to highlight that it can be used to build an endless number of games on sustainability. With 'Sus- $x$ ' we built a first version of our half-baked game which, we ironically called 'PerfectVille' where a good player is one who adopts choices leading to a hectic, consuming, polluting life-style. We iteratively used 'PerfectVille' with our Masters' students to jointly refine it and develop a method of using it with school students. Then in phase 2, we took the latest version of 'PerfectVille' and employed our refined method in school classrooms with 13-15 year olds who engaged in modding 'PerfectVille' in groups of three. In the following sections we briefly describe phase one and then we go deeply in phase two, to discuss the students' elaborations on values around Urban sustainability.

\subsection{Phase 1: Iterative design of the pedagogical intervention}

The pedagogical intervention and the technologies used for phase 2 were the result of iterative design, which expanded in a three year-period and was part of a broader research project (for a detailed description see [38]). In the course of this period we conducted: a) two workshops with teachers and researchers who specialized in Enivronmental Education and Technology Enhanced Learning and b) a pilot study with senior high school students (16-year olds). The inspiration for the half-baked game was based on a game kit coined some years earlier by researchers from the Educational Technology Lab (etl.ppp.uoa.gr) and a group of secondary school students. After the end of this research we developed a web version of this Kit, which 
we call 'ChoiCo', i.e. 'Choices with Consequences' and can be found at http://etl.ppp.uoa.gr/choico. So, 'Sus-x' was a thematic use of 'ChoiCo' focused on sustainability issues. In the context of phase 1 , we designed a first version of 'PerfectVille' using 'Sus- $x$ ' and iteratively refined it with our Masters' students engaging them first in the role of users, then in the role of hackers-modders and finally in the role of educators trying the refined 'PerfectVille' out with some 16 year olds. We employed tools and methods which came out of phase 1 for phase 2 when we went to a secondary school.

So, in phase 1, the first workshop involved seven in-service and pre-service teachers who attended a Master's Program on Environmental Education based at the Environmental Education Lab (eel.ppp.uoa.gr) [39]. The workshop consisted of two face-to-face sessions lasting two hours each and a distance session expanding in two weeks time. The first session took place in the University, in a face-to-face setting, and involved game play with 'PerfectVille', discussion on the half-baked aspects of the game and presentation of the modding tools. The second session focused on game modification and was carried out in distance settings. Teachers worked from home and communicated with digital media to decide and implement the changes of the game. The third session involved the presentation of the modified games and a reflective discussion on their value as expressive media.

One of the findings of this workshop that helped us refine our theoretical grounding was participants' criticism on the half-baked game; specifically, the participants considered that the game allowed only for simplistic integrations of the concept of sustainability. This comment lead to a focus on the axioms integrated in the games [5] and on investigating the learning value in identifying and challenging these axioms instead of creating games that simulate real life.

The second workshop lasted three (3) hours, took place in lab settings, involved two researchers and two of the teachers who participated in the first workshop. The focus of this workshop was for the participants to play the game and discuss its use in the classroom. Results of this workshop lead to a textual description of the pedagogical intervention in the form of activity plan.

The pilot study with students, followed the two workshops, took place in lab settings, lasted two (2) hours and involved two groups of 16 year-old students. In this study two researchers implemented part of the pedagogical intervention focusing mainly on game-play and discussing with the students possible modifications of the game they 
played. The results of this pilot study informed our pedagogical design in that we refined the reflective discussion after game play by contextualizing the half-baked aspects of the game in an interpretive narrative (i.e. what would it mean for you to "live" in the game).

\subsection{Phase 2: A classroom study}

\subsubsection{Broader study}

The data reported here is part of a broader study, which lasted eleven (11) weeks and involved students learning how to learn together when engaged in constructionist and constructivist activities. One of these activities was game design through the process of game modding. Each research session lasted two (2) hours and took place once a week, in the context of an afternoon Environmental Education Club. Eighteen (18) students of a Secondary Experimental School in Athens participated in the larger study. Student age raged between 13, and 15 years. Experimental schools are a special category of public schools in Greece, affiliated with Universities and supervised by a scientific board. The specific experimental school is affiliated with the Educational Technology Lab (etl.ppp.uoa.gr) and was selected to participate in our research due to its willingness to experiment with innovative pedagogical approaches.

In the context of the broader study, students worked in groups of 3. Each group worked with one computer. The line of activities involved: introduction to the task, discussion around the characteristics of collaboration, collaborative creation of a work plan; playing and modifying 'PerfectVille'; presentation of the modified games created by the students; reflection on aspects of sustainability integrated in the games; reflection on the work process based on the work plan.

\subsubsection{Game modding study -participants}

The data analyzed in this paper are derived a) from a classroom discussion after game play and b) from the discourse of two groups of 14-year old students consisting of three boys and three girls. Although all groups were audio recorded, our analysis focused on the specific two groups for the following reasons: a) the synthesis of the groups did not change during the study; b) the two groups consisted a team as they were expected to collaborate during the second phase of the activity; c) from the specific team we collected rich accounts of their decision making process in terms of game modding not only at the group level but also at the level of the team (collaboration of two groups towards the creation of one game). The common interest, 
which connected all the students participating in the study, was environmental awareness. The students did not have any previous experience with game design or game modding. However, all students had experience with digital games (from simple mobile games to complex MMORPGs).

\subsubsection{Role of researchers}

Four researchers and the teacher responsible for the Environmental Education Club were present in the classroom during the study. The researchers undertook the role of participant observer and they intervened in the following cases: a) they provided information (technical information, information about the task) when they considered it necessary or when students asked for help; b) they conducted and facilitated the implementation of the game modding activities; c) they monitored and recorded the activity (by observing, keeping notes, and asking questions). Data collection included student games, screen capturing of student interaction with 'PerfectVille' and student exchanges around it.

\subsection{Outline of the pedagogical intervention}

In the game modding study we report here, we focus on data drawn from two, out of the eleven sessions of the broader study, which lasted six (6) hours in total: In the first session students, in groups of three around one computer, played with 'PerfectVille' (group work) for fifteen minutes. At the end of game play, one of the researchers initiated a whole class discussion where students compared scores and evaluated the game; In the second session, students embarked in modifying 'PerfectVille' so that the player of the game did well when they adopted a lifestyle conducive to a Sustainable city (MySusCity). This activity involved inter and intra-group collaboration. Initially each group took some time to discuss and decide on how they were going to change 'PerfectVille' (inter-group collaboration). Next they were paired with another group, forming a team, to negotiate their suggestions and collaborate in order to create one game. The specific form of collaboration, aimed at triggering discussions at two levels: within the group where students first expressed and formulated their values around basic modifications of the game and between groups where shaped values and ideas were challenged by the members of another group aiming to reach a common understanding and agreement. The third session involved implementation of the changes discussed in Session 2, by each group separately. 


\subsection{Data Analysis method.}

To analyze our data, we employed 'Critical incident' analysis where learning episodes are selected from the corpus of data on the basis of their pertinence to the expression of values in the context of game modding. Critical episodes do not focus on identifying the typical or representative episodes, in the sense that typicality might not always be the key feature [40]. Instead, in terms of learning, the key features consist of breakthroughs and breakdowns [41]. Breakthroughs are episodes where students portray a change in the way they discuss, think, and approach a concept. Breakdowns are episodes where students are struggling with an idea or with a situation, laboring under a misunderstanding and need help. We considered critical incident analysis appropriate for our study as we wanted to identify which aspects of the game modding activity with half-baked microworlds triggered children to express their values and ideas.

In this paper our analysis focuses on critical episodes taken from student discourse during game modding. Student games are not analyzed separately. Instead we view game modding as a process, not as a final product, through the lens of student discourse. This means that we focus on student dialogue around game modding and we investigate how specific student ideas are implemented in their games with the modding tools, although some of these implementations might be discarded in the final game.

\section{PERFECTVILLE AND SUS-X: A HALF-BAKED GAME AND MODDING TOOL}

\subsection{Game play with PerfectVille:}

PerfectVille is a half-baked game to question urban life-styles. It is designed to challenge players to change it because they don't like or agree with the messages it carries for the player or because they find flaws in it [9]. Half-baked games are fully functioning games, which allow players to understand the game mechanics and the basic axioms underlying their design, through game play. However, there is something wrong or faulty either with the game rules, or the content or the values inherent in game-play. So, half-baked games are designed so that they provide a reason to change the game, in order to improve one or more of these elements. The 
pedagogical design that comes with half-baked games envisages game modding through the following steps: First students play the game. The next step - i.e. after game play- is for teachers and/or researchers to orchestrate a structured discussion around the half-baked aspects of the game (i.e. spot what is wrong with the game). After this discussion, the teacher and/or the researcher demonstrates the use of the modding tools and then the students use them to implement the discussed changes in the game.

In 'PerfectVille', the player considers diverse consequences, which will be the result of his/her opting to visit a place in the city. If they take the plunge and actuate the visit the consequences affect a portfolio of values. A good player is the one who stays in the game the longest possible without crossing a red line on one or more of the portfolio values. In order to play, students are expected to decide which sites to visit in 'PerfectVille' in a sequence of 10 possible moves. Some of the sites included in 'PerfectVille' are: library, Dream Soccer Stadium, Restaurant, Disco, Cafeteria, Fast Food Ready's, Airport, Carpender, Home, Chemistry Lab (work) etc. (http://etl.ppp.uoa.gr/choico/)



Fig.1: 'PerfectVille' snapshot

All sites have a specific value with respect to a set of properties: i.e energy, health, money, hygiene, social status and fun. For example if a player decides to go at work 
then his/her money will raise but his/her energy will be reduced radically. Home is a place to go after work to gain more energy. So, while playing (see Fig. 1) students, should consider the following aspects: (a) what are the properties and values of each site; (b) what changes will be caused in the player's 'resources' by choosing to visit one site instead of another; (c) what is the risk of running out of 'resources' before the end of the game (before completing the ten moves in the city). In 'PerfectVille' the half-baked property is expressed -in terms of game play- with the following "flaw": when different groups of students play the game there is no easy way to determine one winner, because the concept of maintaining your resources above a specific threshold is not so challenging in the game. As a consequence, players can take different "paths" in 'PerfectVille': i.e. to focus on fun and social status (eating at the Restaurant, going to the Club, to the cafeteria, to the stadium), to focus on money and energy (going at work and home), to focus mainly on healthy choices etc. This is a design decision with specific implications for the game modding process: It allows for expression of values through game play (each path followed by the player is recorded and indicates a specific life-style); It aims at raising discussions if the game should be modified so as only one property of the game should determine the winner (and which one is it) or if new sites and properties should be added in the game.

\subsection{Modding 'PerfectVille' with Sus-X}

Sus-X is a template microworld from which PerfectVille was created. Sus-X could be considered as a window to the game mechanics of 'PerfectVille', in the sense that students can use Sus-X to implement the following modifications- changes: they can create, load or edit their own city background; they can add site-objects as points on a city-map; they can determine the properties of the sites and the values of each site with respect to these properties; they can define a set of initial and threshold values; they can set the time frame for playing the game or the number of the sites that can be visited; They can define control and end conditions for the game, using rules in the form of "if ... then" expressions (i.e. if Health $<0$ then Game Over see fig.2). In the study we report here, after the discussion around 'PerfectVille', students were prompted to change the game so as to transform 'PerfectVille' to a sustainable City (MySusCity). 




Figure 2. Game modding with SusX: tools for changing parameters and defining rules In Figure 2, we demonstrate the main modding tools used in this study. As opposed to other modding tools that allow access to game rules and game mechanics mainly through programming, in Sus-X the main expression tools are based on tables and "ifthen" expressions. Thus, game elements are items in a database and their properties are fields in the same database. The rules of the game are based on the relationship between items and numeric property values described in the form of "if-then" expressions. For example, in Figure 2, the first rule which ends the game is expressed as follows: if Energy $<0$ and Money $<300$ then Game Over Or If Fun $<0$ then Game Over etc. This type of modding tools consist what we could overstate as "representational system" in the sense that it allows students to express a concept -in this case the concept of sustainability- in the following forms: a) As a set of itemized aspects (game elements) which respond to the question: what are the constituents of a sustainable city? b) As a set of properties attributed to these items. A characteristic which allows for further elaboration on these items (e.g. what is the energy loss for a citizen when going to work); c) As a set of relationships between items and property values (game-rules) which determine the mode of living in the game city and the interaction with the game world.

\section{RESULTS}


The sstudents' engagement with game modding focused mainly on changes of the background picture of their game, on the sites of the new game, on the addition of two new parameters - pollution and time-, and on the ensuing value consequences. Unfortunately, there was no time for them to tinker with the rules corresponding to game ending or those related to adding commentary related to aggregate numerical field values. Had they had more classroom time it would have been quite natural to follow on to these modding issues. So these are in essence the game-modding activities on which we report here. With respect to overall game rules, since the students did not delete any of the initial parameters of 'PerfectVille' (e.g. fun, energy, health etc) their end game seemed at first sight very similar to 'PerfectVille'. In reality however, the moddings they made can be argued that radically changed the values embedded in playing the game. In the table below we present the critical episodes we selected from the 6-hour study and the context in which it occurred.

\begin{tabular}{|l|l|}
\hline \multicolumn{1}{|c|}{ CRITICAL INCIDENT } & \multicolumn{1}{|c|}{ CONTEXT } \\
\hline $\begin{array}{l}\text { Transcript 1. Challenging 'PerfectVille': } \\
\text { Connecting game rules with values of life }\end{array}$ & Session 1: Whole class discussion \\
\hline $\begin{array}{l}\text { Transcript 2: Compromising between } \\
\text { pollution and time in a sustainable city }\end{array}$ & $\begin{array}{l}\text { Session 2: Inter-group discussion on } \\
\text { deciding the parameters of the game. } \\
\text { (Group A) }\end{array}$ \\
\hline $\begin{array}{l}\text { Transcript 3: Choosing the background } \\
\text { picture of the game and demonstrating a } \\
\text { sense of ownership }\end{array}$ & $\begin{array}{l}\text { Session 2: Intra-group discussion on } \\
\text { agreeing about the background image of } \\
\text { the game (Group A and Group B) }\end{array}$ \\
\hline $\begin{array}{l}\text { Transcript 4: Humor as an element of } \\
\text { the modded games }\end{array}$ & $\begin{array}{l}\text { Session 3: Inter-group discussion on the } \\
\text { sites of "mySusCity". Two extracts from } \\
\text { Group A and Group B }\end{array}$ \\
\hline
\end{tabular}

Table 1: Critical incidents and context of occurrence

Our analysis showed that students expressed their values at two levels. The first level involves values connected to urban life. In this level, students negotiated the integration of the concept of sustainability in the game, in terms of corresponding life style (i.e. green spots are connected to health and leisure, or amusement is important in life). The second level involved a set of personal values, which were expressed in 
reference to level one (e.g. from good or bad decisions to compromises) and in reference to the change of the game (i.e. sense of ownership and humor). The ensuing presentation of results follows this progressive appearance of personal values.

\subsection{Challenging the Value Assumptions of the Game}

Game modding involved an often seamless interchange of role for the students from that of player to that of re-designer. Our students engaged with both, identifying the game mechanics and the half-baked aspects of the game. We mentioned earlier that we orchestrated a reflective discussion on game play as a basis for the game modding process. Our rationale underlying this discussion was to help students progressively cultivate a mindset where they became critical of the main axioms integrated in the game. Usually, when students play a game, they try to understand its mechanics to the extent that this allows them to formulate a successful game play strategy. In this context there is no space for a critical view on the axioms integrated in the game and that is the gap our intervention aimed to cover.

The extract below is taken from classroom discussion around who might be the winner of the game. Score comparison as a topic of discussion served as an incentive for the students to: a) develop a shared understanding of the criteria they employed to win the game, and b) to collaboratively identify how these criteria correspond to a particular profile or model of life. We mentioned earlier, that the player's decision to actuate a visit to one of the ten places had a numerical effect on the aggregate value corresponding to each of the game's fields. The gaming idea was that each visit would have conflicting consequences, i.e. some positive effects on certain fields and some negative on others. The point of the game was to avoid crossing a 'red line', i.e. to go above or below (according to what made sense) a certain score for each one of the fields. 'PerfectVille' was designed as a half-baked game to be quite easy not to lose after 10 visits, so that the students would quickly realize that the embedded rules would need to change to make the game more challenging. Thus at the end of the initial game-play all student groups 'won', i.e. no one crossed a threshold. The ensuing discussion for the winner, focused on the values of the specific parameters constituting the score (i.e. total value of energy, money, health etc). 
3. S1- We won, because we have the largest amount of money: 1200

4. S8: Who said that money was most important for the game? All you did was to go from work to home and vice versa

5. S5: I think we won, cause we have the highest energy levels and the highest social status

6. S11: Wait, wait. The winner is the one who has the highest values in all these: money, energy, fun, social status, health, hygiene.

7. R1: What kind of life do you have to live in order to achieve that?

8. S16: You have to do a lot of everything: have a lot of fun, have a lot of money...

9. S3:You have to be a freak to live like this..

Transcript 1. Challenging 'PerfectVille': Connecting game rules with values of life

In the student dialogue above, we identify two instances that can be related to the values of urban life. One involves an assumption that relates the winner with the amount of money collected (line 3). However, a student from another group challenged this assumption at two levels: at the level of game rules (who said that money was most important to win the game) and at the level of life- style (all you do is go from work to home and vice versa). As we mentioned earlier, the design of 'PerfectVille' affords winning by allowing players to create different visiting sequences (paths) in the city in terms of choosing city sites which, in turn, constitute different life styles (i.e. emphasizing social life or money and fun etc). The students suggested three alternative distinct rules for winning. In the first, the winner is the highest scorer in money, in the second the winner is the highest scorer in two fields, energy and social status and in the third the highest scorer in all fields together. So, estimation, aggregate scores, simple arithmetic which could easily become more complex as far as game theory was embedded in the half-baked game. Issues like 'if it's the first solution did scores on other values have no effect whatsoever?' or, 'were energy and social status considered of equal value?', or what about the relative numerical values and increments, e.g. 'how did one euro in salary terms compare to one measure of energy?'. The students however only referred to such issues implicitly or not at all. What prevailed in their discussion was what does it mean to win, what kind of life-style does the game promote? Two game-play styles emerged which express two different sets of values about living in the city. In the first part of the discussion (lines 1-4) students described a game-play, which expresses values focused on quiet domestic life and work. Another style of game-play relates winning in 
'PerfectVille' with a hectic way of living (lines 8 and 9), as students realized that the actual winning group should have the highest score in all parameters even though they did not specify exactly what that would mean. As a conclusion in this episode, the game-play strategy depicted in the score (which parameter was emphasized the most) captured implicitly a "life-style" and a decision of what "matters most" in order to live in 'PerfectVille' and that was the students' interpretation of what was the assumption of the game. The reflective discussion on score comparison created opportunities for students to elaborate and challenge game play strategies (i.e. the criterion underlying the selection of sites) on the basis of game rules and inferred lifestyles in 'PerfectVille'. This discussion progressively led students to identifying the game mechanics for wining in 'PerfectVille' they decided on high scores in every parameter and to describing and challenging the main assumption of the game regarding life in 'PerfectVille', i.e. that it promoted a hectic way of living. Next we present how students used the modding tools to express new assumptions about a sustainable way of living.

\subsection{From Radical Solutions to Compromises}

Sus- $\mathrm{X}$ was presented to the students as a tool to change 'PerfectVille' so as to represent a more sustainable way of living in the city. The following episode is from the second session where students were expected to first discuss the changes in their game in their group. The discussion evolved as students started tinkering with the actual game. This means that their discussion around changes evolved as they were changing the game and did not have the form of a verbal discussion away from the computer. In the dialogue below, students had already added the parameter of pollution in their game. In terms of game modding, this decision was implemented with the addition of a new field in the database (see Figure 2). In terms of game play, this modification introduced the environmental footprint as a critical element for the player's choices, as opposed to money, energy and fun which formulated the game play with 'PerfectVille'. Moreover, it inserted a negative numerical value rationale, the higher the value of pollution the worse for the player. Pollution, being a critical parameter of the modified game, influenced the investigation of other choices such as transportation in the city:

1.S1:I am not sure about not having cars in the city. 
2. S2: I am telling you, it has been done in Freiburg. Cars mean pollution.

3: S1. Yes, but imagine how much more time you will need if you go at work by bicycle. You have to wake up at least one hour earlier.

4. S3:Ok then, we will add time in the indicators. Taking the bicycle will result in reducing pollution and raising time.

Transcript 2: Compromising between pollution and time in a sustainable city

In this discussion, which was recorded during the game modding activity, we identify a set of interesting ideas about sustainability: a) sustainable cities do not have cars (line 2) b) cars are equal to pollution (line 2) and c) transportation is an issue related to time which is an important value of urban life (line 3). These might be simplistic assumptions about sustainability and in the context of the game, students have the freedom to experiment with radical solutions (like forbidding cars from a city). However, by integrating in the game the dimension of time and implicitly relating it to pollution (line 4), students depicted the aspect of compromises often encountered in real life. So, increase in time to work was also worse for the player just like pollution was. This compromise was in any case an important shift from the radical solution of forbidding cars, because it points to the belief that there are no clear-cut solutions (i.e. only good or only bad), which is a key approach, in addressing open ended and complex situations.

\subsection{Half-baked games: Sense of Ownership and Value Expression}

Modification of the game space, which in this case was the background picture of the city, is a game modding activity not simply supported by the digital tools we present here, but also integrated in the pedagogical design as a rich learning activity. Researchers provided a set of seven chosen pictures to the students and pointed out that the criterion for their selection should be formulated on the basis of the properties of a sustainable city. The collaboration scheme during the game modding activity involved inter-group and intra-group collaboration. Each group took some time alone to discuss modifications of the initial game in an intergroup collaboration. When each group reached consensus, they discussed their ideas with the collaborating group (intra-group collaboration) with the aim to agree on the elements of the new game (sites, background, parameters and rules). In the episode below, we present an extract of intra-group discussion around the background of the common game. Each of the 
groups during their inter-group discussion selected a different picture as a suggested background of their game (see Figure 3 and Figure 4).

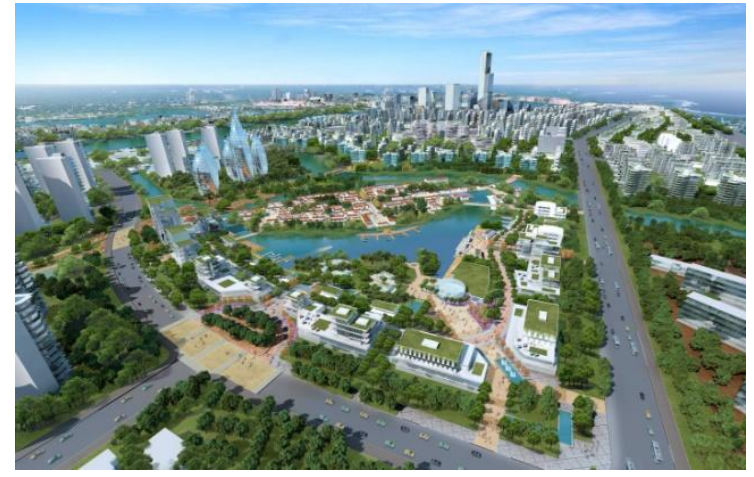

Figure 3. ETL2-Picture 6: Skyscrapers can have a place in a sustainable city



Figure 4. ETL 1-Picture 9: A sustainable city with green spots and leisure activities for the citizens

The mode of intergroup communication was face-to-face, whereas intragroup communication was mediated by a chat tool. This setup allowed for the members of each group to discuss within their group their arguments before writing them in the chat. By setting up two different modes of discussion we aimed at gaining a more clear insight on the rationale underlying the student exchanges in the Chat. Below we present the intragroup communication using the code names ETL1 and ETL2 for each group. In the episode, we have also captured a verbal exchange (not written in the chat) between students S4 and S5 who are members of ETL2 group and an exchange between a researcher and $\mathrm{S} 4$.

$1 \quad$ ETL1: We suggest that we use 9. What do you think?

2 ETL2: Why should we use 9?

3 ETL1: Because it is less inhabited and with fewer cars

4 ETL2: In [picture] 6, there are more trees and more pleasant activities (for the citizens)

$5 \quad$ ETL1: Yeah, ok (sarcastically)

6 ETL2: But [picture] 9 is packed

7 ETL1: Yes but the one we suggest has more water

8 ETL2: Yes. Salty water. Our city has salty and drinkable water.

9 ETL1: Why? Doesn't 6 has salt?

10 S4 to S5 (of ETL2) Our city - we are talking as if it is indeed ours [laughing]- has rivers, lakes and sea

11 ETL1: Yes, but there is a problem: the skyscrapers

12 ETL2: But check out [picture] 6 for a while. It is a good choice for a sustainable city. It is more open and there is more space as opposed to [picture] 9 where inhabitants are packed like sardines in a box [direct translation of the Greek saying used by the students].

13 Rl: Have you finished with your map? 
$14 \quad$ S4: $\quad$ Not yet. We can't agree on which picture to use. We are supporting one and they are supporting another

15 ETL1: A sustainable city for us, is a city without skyscrapers. Second: it is necessary to be green (in the sense of having trees and parks) and to have water.

16 ETL2: A sustainable city for us is a city with a lot of green (i.e. trees). Besides in our picture there are trees inside the city and thus the air is cleaner. In the city of your picture, there are not so many trees and all the exhaust gas remains in the air of the city, which might cause health problems to your citizens. Furthermore we have only one skyscraper in a place where there are a lot of trees.

17 ETL1: and of course the sea which makes the climate milder. And there are trees. Furthermore, our city has less cars than yours

18 ETL1: Much less cars.

19 ETL1: !!!

20 ETL1: and your citizens are isolated because they live in skyscrapers

21 ETL2: We don't think so. In our city there is sea, lakes, rivers, blocks of flats, houses. There are trees everywhere, the cars are not that many in comparison to those of a normal city. In your case water supply is not that easy whereas in our case there is drinkable water [Probably they consider the river and the lake]. Imagine the construction work you need in order to supply water to your city from say $200 \mathrm{~km}$ away. Additionally in our city there are trees everywhere. In your city there are places with no trees at all which might cause health problems. Think about this...

Transcript 3: Choosing the background picture of the game and demonstrating a sense of ownership

In the episode above, the disagreement between the two groups triggered a discussion around the sustainable characteristics of the city depicted in the picture they selected, so that they could convince the other group for the validity of their suggestion. As this discussion evolved, more characteristics of a sustainable city came into play with each group trying to provide a definition (a sustainable city for us is.... lines 15 and 16). There are two "layers" in the student exchanges about sustainable cities. One involves infrastructure: parks, cars, open spaces, water and housing density. The other layer incudes the values linked to this infrastructure: leisure activities (line 1), access to water, healthy environment, social interaction (vs isolation line 21) and population density (i.e. ensuring enough space for the citizens- lines 6 and 12). Students build their arguments on connections between the two layers. This way they "interpret" the infrastructure to a set of values that underline a desirable and sustainable way of living. It is exactly this interpretation of infrastructure to life styles that makes their arguments clear and convincing. The groups were so immersed in this discussion that 
they did not have the time to address the other elements of the game (parameters, rules). The session finished and the groups did not reach consensus at the end. As a result the groups decided to deviate from the task and to construct two different games instead of one, working separately.

A question that seems relevant to investigate now is what is behind this long discussion, which allowed students to express their values. One interpretation involves the type of the task. It appears that open-ended problems (like arguing about the selection of one picture), with not one right or obvious solution, can trigger students to express their values and ideas. However, it is important that this type of problems are integrated in a task with personal meaning for the students.

By integrating an open-ended problem, like the one discussed above, in the context of a half -baked game, we observed that students seem to have developed a sense of ownership over the game they are constructing. This is evident in the language they use "our city, our picture" and it is also noted by the students themselves "Our citywe are talking as if it is indeed ours" (line 10). Ownership is considered an important attitude towards learning because it formulates the basis for intrinsic motivation and student engagement. Based on this analysis, ownership can possibly explain student engagement in a long discussion, interest in elaborating on ideas and deviation from the task when consensus is not reached. Game modding with half-baked games seem to facilitate the development of ownership because it is a personally meaningful task and it supports students not only to modify the game according to their taste and ideas but also to construct, overcoming technical difficulties, a functional final product for which they can be proud of.

\subsection{Humor in modded games}

We mentioned earlier that students of the two focus groups worked separately and they created two different games instead of one. Below we present in one table two transcripts, which are presented together because they have a common element: expression of humor. The episodes are drawn from both groups of our study in the session during which students discussed and added the sites of their "sustainable city" games.

\begin{tabular}{|l|l|}
\hline $\begin{array}{l}\text { 1. Rl Does this add at all to building } \\
\text { the idea of sustainability in a city? }\end{array}$ & $\begin{array}{r}\text { 1. Rl Let's have a look at the places } \\
\text { you have added in your city. Are they } \\
\text { all necessary for your sustainable }\end{array}$ \\
\hline
\end{tabular}




\begin{tabular}{|c|c|}
\hline $\begin{array}{l}\text { "bouzoukia" in a city satisfy? } \\
\text { 2. S2 They are for the entertainment of } \\
\text { our visitors! (S2 is being humorous } \\
\text { about a city's contentious provisions } \\
\text { for tourists) } \\
\text { 3. R1 What else is it necessary in a city } \\
\text { like that? In your sustainable city. } \\
\text { 4. S3 There is a cinema. } \\
\text { 5. S1 Above all there should be a park. } \\
\text { And then a cinema. A gym, which we } \\
\text { have to add, it is still there. } \\
\text { Group A }\end{array}$ & $\begin{array}{l}\text { city? } \\
\text { 2. S4 Yes! } \\
\text { 3. S5 Who can live without fast-food? } \\
\text { Without French fries? } \\
\text { 4. R1 How sustainable is to eat in a } \\
\text { fast-food? } \\
\text { 5. S4 Very much! [S4 laughs]. } \\
\text { 6. R1 Perhaps it would help to think } \\
\text { what is sustainable and what is not, if } \\
\text { you take a closer look at all these } \\
\text { criteria or values, whether they can } \\
\text { stand as indicators of sustainability... } \\
\text { 7. R1 Is entertainment adding to the } \\
\text { sustainability of a city? } \\
\text { 8. S4 Well yes! Life has to be } \\
\text { interesting and not boring! } \\
\text { Group B }\end{array}$ \\
\hline
\end{tabular}

Transcript 4: Humor as an element of the modded games.

The data we collected from all the groups that were engaged with game modding showed several instances where students exchanged jokes and were humorous with what they were doing. The extracts we present above distinguish from the rest because they are instances where students actually integrate humor in their game.

In both episodes students initially have inserted a rather "provocative" site in their city trying to be humorous. In the first case they added bouzoukia (Group A), which is a way of entertainment appealing to a certain group of people and for some it is considered low culture. This might be the reason (i.e. low culture) that students do not identify with this type of entertainment and when asked they assert that they put it in the city for the entertainment of the tourists. In the second case (Group B) students added fast food, connecting here sustainability with junk food "who can live without fast food and French fries" (Group B, line 3). In both cases none of these places bouzoukia or fast food- can be considered as sustainable choices. However students add them in their game. We interpret this as an effort to be playful and creative with a rather serious, complex and difficult concept (that of sustainability), which is an indicator of ownership and use of the game as a medium to express a very personal touch such as humor. We consider humor as an indicator of ownership because it shows that students do not just execute the task. Instead they are playful with it and they are interested in making their game special by adding humorous elements in it. 
Furthermore students, working in the context of game modding, seem to delve into the concept of sustainability in a way that allows them to be creative with it as they dare to consider also what is a non-sustainable choice. The game modding tools offered students the expressive power - or to put it in another way removed the technical barriers- to integrate humor in their construction. Yet, tools alone do not offer a sufficient account for the integration of humor in student games. We also need to consider the whole pedagogical intervention, which aimed at cultivating a mindset of challenging a ready-made game (i.e. 'PerfectVille'), identifying provocative elements in it (hectic life style) and tinkering creatively with it.

From the point of view of values expressed with regard to a sustainable life style, student discussion with the reviewer brought into the foreground the following ideas: a) amusement is an essential part of life b) a sustainable city should offer opportunities for the citizens to spend their free time (like park, gym, cinema) and c) there is no quality of life in a city where citizens do not have fun and they are bored.

\section{DISCUSSION}

This study left us with the feeling that pedagogically orchestrated game modding can be very engaging for young people and provide them with a sense of relevance and ownership in their dialogues and their productions. In this sense, this kind of context can be particularly rich in opportunities for elaboration in child activity and the sense of being a genuine design partner together with the researchers (in the sense of [15]). In a modding activity such as this, children and researchers discuss design issues whilst engaged in literal creation of a prototype product. We found this experience to be deeply illuminative of children's urban sustainability values and at the same time to be potentially valuable to them to express, question and generate their own values around the subject. Modding and discussion around the process of modding focused, organised and helped elaborate their ideas and views. So, rather than deciding in advance what are the 'socially accepted' or 'appropriate' values regarding an issue where these are contested and vaguely understood, we allowed and encouraged the children themselves to express, question and refine their own value systems and acted as co-discussants and critical friends. Admittedly, we did embed rules and values in 'PerfectVille' and these were skewed so as to generate discussion as a result of the need to change and improve the game. However we were open to see how the 
children would interpret these values and to encourage them to change the game in ways in which they felt appropriate.

Our ChoiCo/Sus-x tool allowed us to design a game intended to engage our students even more in a reflective discussion on embedded values and in meaning-making regarding a complex contentious issue rather than a silo domain involving traditional curriculum concepts. In that sense, 'PerfectVille' operated as a context simulator, structuring the learning environment so that, through the process of hacking a game and modding it, students would have a dense opportunity to elaborate on value - laden and logical issues in an integrated way. For instance, considering the societal value of a hectic life-style came up while they were discussing a gaming idea, in the midst of hacking a game with an unconventional win status [10], i.e. who is a winner in 'PerfectVille'. At first, the students connected the value of making money as opposed to that of scoring on energy and social status. Then they discussed scoring high on all values without prioritization to their personal lives rather as opposed to scoring high on those values promoting environmental issues involving sustainability. There were also implicit logical and mathematical ideas embedded in scoring and in addressing the programmed rules for the 'red lines', such as 'you lose when your money is below zero'. The students seemed to be aware of them but in this case did not turn them into objects of discussion. Had there been a pedagogical agenda and available time for this to happen, however, moments like the one depicted in transcript 1 would provide an excellent opportunity to focus on STEM concepts. Nevertheless, the students employed the data-base design affordances to discuss pollution versus time to-andfrom work as an environmental issue connected to a sustainable city. We found it interesting that they naturally thought of the conflicting potentially contentious character of pollution versus time and that in this problem there was no one solution or correct answer but rather the issue of a compromise to be made. We were surprised by how much time was spent and how much vested the students were to argue for the choice of 'the city map'. They connected the semantics of the maps to their personal views of sustainable cities and perceived of locations as pertinent to the game, i.e. to the places to be visited and the consequences of such visits. Although the student groups did not all have the time to fully complete and test a working mod, they felt as if they were engaged in a process which would lead to that moment and personalised the changes they made to include locations intentionally thought of as 'negative' for winning the game. So, they considered actions such as going to low-level clubs or 
eating junk food as not conducive to a sustainable city but included them in their mod to make the game interesting and challenging. Also perhaps to make the game educational, lead the player to consider the negative aspects of these particular visits at least frequently.

As researchers, we felt daunted by the complexity of the phenomenon at hand, i.e. to figure out what meaning students generated and how these were created in interaction with the half-baked game affordances and their ensuing negotiations for modding. An endogenous game operating as a context for domain concepts and values within complex issues requires very careful design in order to become educationally valuable and help students focus on the issues at hand. Hacking a game may thus facilitate in unique ways the process of students identification of values embedded in a game but also the process of their becoming conscious of values they implicitly host themselves. It may well be worth-while developing rubrics charting the diverse concepts, values, skills and competences in such activity. As educators however, we found 'PerfectVille' and the affordances of Sus-x as tools, which really supported our pedagogical intervention in student discussions and modding efforts. Such tools for modding games can be considered as expressive media, as tools by means of which students express their ideas, values and meanings. The experience may also provide students with a critical eye for commercial games and the values and assumptions embedded in these.

\section{CONCLUSION}

This paper addresses the challenge of creating deep educational and personal value for children to adopt the role of partners in game design by means of hacking and modding value-laden games designed to invite such modding. Having been engaged in experiences dense in opportunities for meaning-making and gaining sensitivities to values, children may become better at playing an important part in game design processes in general.

So far, in education, values have been perceived as distinct from domain specific or trans-disciplinary education such as STEM where powerful ideas, inquiry and rigor have been addressed as the priority objectives [9, 42]. Post-positivist paradigms however, strive to confront children with complex contextualized issues such as urban sustainability [41]. Such issues embed personal and negotiated values, place-based knowledge, behaviors and habits in situations where science and mathematics provide 
tools to grapple with value-laden multi-faceted problems $[42,43]$. This may be a great opportunity for pedagogical engineering focusing on providing students with half baked games as simulations of structured contexts dense in opportunities for identifying, challenging and forming values during individual and collaborative work. For example, tools for game modding can be used for students to learn about sustainability, embedding rules and values in a programmable, geo-coding system such as Sus-x and appreciating that all these are just means to engage in discussion around complex issues where citizen behaviors and habits are in question in agendas for change. In the study, we found the idea of designing half-baked games for learning through modding useful in structuring a context for the students to work in. Pedagogical intervention provides further capability to steer meaning-making to address concepts and values in an integrated way.

Even though this context was educational, it had a prevalent element of design addressing both our masters' students and our school children as design partners in the process of prototyping an urban sustainability game. Tinkering with and changing a half-baked product illuminated our partners' elaborations on both game rules and values and provided us with insight, which we could use in a subsequent iteration leading to both a new half-baked game and an end product. So, collaboratively hacking and modding games may be considered as a means to get everybody to design and for professional designers to consider ways of interacting with such ubiquitous design cultures. The potential for mods to become objects of discussion in student communities is interesting and requires further study. This whole venture, although designed within an educational context, may well produce new ideas for the gaming industry, especially though initiatives such as competitions and sponsored events.

\section{ACKNOWLEDGEMENTS}

This study is funded by EU-R\&D project "Metafora - Learning to Learn Together: A visual language for social orchestration of educational activities" (EC/FP7, Grant agreement: 257872)

\section{REFERENCES}

[1] M. Flanagan, H. Nissenbaum, Values at Play in Digital Games, MIT Press, 2014. 
[2] J.A. Fails, M.L. Guha, A. Druin, Methods and Techniques for Involving Children in the Design of New Technology for Children., Found. Trends ${ }^{\circledR}$ HumanComputer Interact. 6 (2013) 85-166.

[3] C. Kynigos, Half-baked Logo microworlds as boundary objects in integrated design, Inform. Educ. 6 (2007) 335-358.

[4] T. Bekker, S. Bakker, I. Douma, J. van der Poel, K. Scheltenaar, Teaching children digital literacy through design-based learning with digital toolkits in schools., Int. J. Child Comput. Interact. 5 (2015) 29-38.

[5] N. Yiannoutsou, C. Kynigos, M. Daskolia, Constructionist Designs in Game Modding: The case of learning about Sustainability, in: G. Futschek, C. Kynigos (Eds.), Proc. Constr. 2014 Constr. Creat., Vienna-Austria, 2014: pp. 459-469.

[6] L. deValk, T. Bekker, B. Eggen, Drawing up the rules: encouraging children's rule creation in interactive open-ended play, Int. J. Child Comput. Interact. 2 (2014) 120-129.

[7] J. Dillon, On learners and learning in environmental education: Missing theories, Ignored communities., Environ. Educ. Res. 9 (2003) 215-226.

[8] C. Kynigos, Designing Constructionist E-Books: New Mediations for Creative Mathematical Thinking?, Constr. Found. 10 (2015) 305-313.

[9] C. Kynigos, F. Moustaki, Designing digital media for creative mathematical learning, in: Proc. 2014 Conf. Interact. Des. Child., Aarhus, Denmark, 2014: pp. 309-312.

[10] J. Belman, M. Flanagan, Exploring the Creative Potential of Values Conscious Design: Students' Experiences with the Values at Play Curriculum, Eludamos J. Comput. Game Cult. 4 (2010) 57-67.

[11] R. Caillois, Man, Play and Games, University of Illinois Press., Chicago, 1961.

[12] J. Huizinga, Homo ludens a study of the play-element in culture, Routledge and Kegan Paul, London; Boston, Mass., 1998.

[13] I. Bogost, Procedural Literacy: Problem Solving with Programming, Systems, \& Play, Telemedium. (2005) 32-36.

[14] M. Mateas, Procedural literacy: Educating the new media practitioner, in: D. Davidson (Ed.), Fun Serious Games Media, ETC Press, Pittsburgh, PA, USA (C)2008, 2008: pp. 67-83.

[15] W. Barendregt, M.M. Bekker, P. Börjesson, E. Eriksson, O. Torgersson, The Role Definition Matrix: Creating a Shared Understanding of Children's Participation in the Design Process, in: IDC 16, Manchester, United Kingdom, Manchester, United Kingdom, n.d.: pp. 577-582.

[16] J. Piaget, Play, Dreams and Imitation in Childhood., Heinemann, London, 1951.

[17] S. Papert, Mindstorms: Children, computers, and powerful ideas, Basic Books, Inc., 1980.

[18] Y. Kafai, Minds in play: Computer game design as a context for children's learning, Lawrence Erlbaum, Mahwah, NJ, 1995.

[19] E.R. Hayes, I.A. Games, Making Computer Games and Design Thinking: A Review of Current Software and Strategies, Games Cult. 3 (2008) 309-332. doi:10.1177/1555412008317312.

[20] K. Salen, Gaming Literacies: A Game Design Study in Action, J. Educ. Multimed. Hypermedia. 16 (2007) 301-322. 
[21] Y.B. Kafai, Q. Burke, C. Mote, What makes competitions fun to participate?: the role of audience for middle school game designers, in: Proc. 11th Int. Conf. Interact. Des. Child., ACM, 2012: pp. 284-287.

[22] T. Sihvonen, Players unleashed! Modding the Sims and the culture of gaming, Amsterdam University Press, Amsterdam, 2010.

[23] C. Kynigos, Using half-baked microworlds to challenge teacher educators' knowing, Int. J. Comput. Math. Learn. 12 (2007) 87-111. doi:10.1007/s10758007-9114-2.

[24] O. Sotamaa, When the Game Is Not Enough: Motivations and Practices Among Computer Game Modding Culture, Games Cult. 5 (2010) 239-255. doi:10.1177/1555412009359765.

[25] A. Moshirnia, The Educational Potential of Modified Video Games., Issues Informing Sci. Inf. Technol. 4 (2007).

[26] J. Robertson, C. Howells, Computer game design: Opportunities for successful learning, Comput. Educ. 50 (2008) 559-578.

[27] E. Westecott, Crafting play: little big planet, Loading... J. Can. Game Stud. Assoc. 5 (2011) 90-100.

[28] A. Baytak, S.M. Land, B.K. Smith, Children as Educational Computer Game Designers: An Exploratory Study., Turk. Online J. Educ. Technol. 10 (2011).

[29] M.S. El-Nasr, B.K. Smith, Learning through game modding, Comput. Entertain. CIE. 4 (2006) 7.

[30] I. Yucel, J. Zupko, M.S. El-Nasr, IT education, girls and game modding, Interact. Technol. Smart Educ. 3 (2006) 143-156. doi:10.1108/17415650680000059.

[31] B. Monterrat, E. Lavoué, S. George, Learning Game 2.0: Support for Game Modding as a Learning Activity, in: Proc. 6th Eur. Conf. Games Based Learn., 2012: pp. 340-347.

[32] M. Ulicsak, M. Wright, Games in Education: Serious Games, Futurelab, 2010.

[33] K. Squire, From Content to Context: Videogames as Designed Experience, Educ. Res. 35 (2006) 19-29. doi:10.3102/0013189X035008019.

[34] S. Turkle, From Powerful Ideas to PowerPoint, Converg. Int. J. Res. New Media Technol. 9 (2003) 19-25. doi:10.1177/135485650300900204.

[35] D.G. Lobo, A city is not a toy: How SimCity Plays with Urbanism, London School of Economics and Political Science, Cities Programme, 2005. http://www.deaquellamanera.org/files/Lobo_CityToy05LSE.pdf (accessed March $16,2014)$.

[36] D. Joseph, The Practice of Design-Based Research: Uncovering the Interplay Between Design, Research, and the Real-World Context, Educ. Psychol. 39 (2004) 235-242. doi:10.1207/s15326985ep3904_5.

[37] The Design-Based Research Collective, Design-based research: An emerging paradigm for educational inquiry, Educ. Res. (2003) 5-8.

[38] N. Yiannoutsou, C. Kynigos, Boundary Objects in Educational Design Research: designing an intervention for learning how to learn in collectives with technologies that support collaboration and exploratory learning, in: T. Plomp, N. Nieveen (Eds.), Educ. Des. Res. Introd. Illus. Cases, SLO, Netherlands Institute for Curriculum Development, Enschede, The Netherlands, 2013: pp. 357 - 379.

[39] M. Daskolia, C. Kynigos, N. Yiannoutsou, Teachers learning about sustainability while co-constructing digital games, in: Int. Conf. High. Educ. ICHE 2012 27-28 June 2012, Paris - France, 2012. 
[40] D. Scott, M. Morrison, Key ideas in educational research, Continuum, London; New York, 2006.

[41] S. Anastopoulou, M. Sharples, M. Wright, H. Martin, S. Ainsworth, S. Benford, C. Crook, C. Greenhalgh, C. O'Malley, Learning 21st century science in context with mobile technologies, (2008). http://oro.open.ac.uk/31290/ (accessed August 10, 2013).

[42] B.. Stevenson, Schooling and environmental education: contradictions in purpose and practice, Environ. Educ. Res. 13 (2007) 139-153.

[43] M. Daskolia, C. Kynigos, Applying a Constructionist Frame to Learning about Sustainability, Creat. Educ. Issue High. Educ. 3 (2012) 818-823. doi:DOI:10.4236/ce.2012. 